\title{
Strain-to-strain variation of Rhodococcus equi growth and biofilm formation in vitro
}

\author{
Adina R. Bujold, Nicholas R. Lani and Macarena G. Sanz
}

\begin{abstract}
Objective: Rhodococcus equi is an opportunistic pathogen that causes disease worldwide in young foals and immunocompromised humans. The interactions of $R$. equi with the host immune system have been described; however, most studies have been conducted using a few well-characterized strains. Because biological differences between R. equi strains are not well characterized, it is unknown if experimental results will replicate when different strains are used. Therefore, our objective was to compare the growth and biofilm formation of low-passage-rate clinical isolates of $R$. equi to higher-passage-rate, commonly studied isolates to determine whether strain-to-strain variation exists.

Results: Twelve strains were used: 103+, ATCC 33701, UKVDL206 103 S harboring a GFP-expressing plasmid, a plasmid-cured 33701 (higher-passage-rate) and seven low-passage clinical isolates. Generation time in liquid revealed fast, moderate-fast, moderate-slow, and slow-growing isolates. The higher-passage-rate isolates were among the moderate-slow growing strains. A strain's rate of growth did not correspond to its ability to form biofilm nor to its colony size on solid media. Based on our results, care should be taken not to extrapolate in vitro work that may be conducted using different $R$. equi strains. Further work is needed to evaluate the effect that the observed differences may have on experimental results.
\end{abstract}

Keywords: Rhodococcus equi, Strain-to-strain variation, Growth, Biofilm

\section{Introduction}

Rhodococcal pneumonia is an important cause of morbidity and mortality in young foals worldwide and an emerging opportunistic pathogen of immunocompromised humans [1]. The etiologic agent, Rhodococcus equi, is a Gram-positive, aerobic, soil-dwelling opportunistic pathogen [2-4]. Inside the host, it is a facultative intracellular pathogen that replicates within macrophages, where it prevents acidification of the phagolysosome $[5,6]$. Despite characterization of the immune system's interactions with this organism and the identification of some virulence factors of $R$. equi [7], understanding of its pathogenesis is limited. The virulence-associated plasmid (VAP), and VapA in particular, is critical for virulence in horses and is routinely used to differentiate pathogenic from non-pathogenic strains $[8,9]$. Virulence determinants appear to be conserved in the core genome of $R$.

\footnotetext{
*Correspondence: macarena@wsu.edu

Department of Veterinary Clinical Sciences, Washington State University,
} Pullman, WA, USA equi $[10,11]$, but differences in their expression have yet to be characterized.

Several genotypically distinct isolates of $R$. equi have been obtained from soil, air, water, and feces at horse breeding farms $[12,13]$, but the majority of studies to date have been conducted using a few relatively well characterized strains $[2,7,14,15]$. The advantage to this approach is reproducibility among studies and the ability to build on previous work. However, it is hard to predict if the observed results will be replicable using different strains. Therefore, our objective was to compare the growth and biofilm formation of low-passage-rate clinical isolates of $R$. equi to commonly studied and higher-passage-rate isolates to determine whether strain-to-strain variation exists.

\section{Main text \\ Methods}

Bacterial strains

Strains used in this study are listed in Table 1. Strains chosen include previously studied and higher-passage-rate 
Table 1 Bacterial isolates of Rhodococcus equi used in this study

\begin{tabular}{|c|c|c|}
\hline Isolate & Characteristics & References \\
\hline $103+$ & Isolated from pneumonic foal & {$[29]$} \\
\hline 103S-GFP & Subculture of $103+$ strain harboring pGFPmut2 plasmid & {$[30]$} \\
\hline ATCC 33701 & Isolated from horse lung & {$[31]$} \\
\hline ATCC 33701 pc & Plasmid cured strain of ATCC 33701 & {$[9]$} \\
\hline UKVDL206 & Virulent clinical isolate collected by the University of Kentucky Veterinary Diagnostic Laboratory & {$[16]$} \\
\hline WSU001 & Clinical isolate collected from human & This study \\
\hline WSU002 & Clinical isolate collected from foal & This study \\
\hline WSU003 & Clinical isolate collected from foal & This study \\
\hline WSU004 & Clinical isolate collected from foal & This study \\
\hline WSU005 & Clinical isolate collected from foal lung & This study \\
\hline WSU006 & Isolated from osseus manifestation of disseminated rhodococcosis in a foal & This study \\
\hline WSU007 & Isolated from transtracheal wash in a foal & This study \\
\hline
\end{tabular}

isolates ATCC 33701, 103+, and UKDL206 [16, 17], ATCC 33701 strain that was cured of the VAP, and a subcultured $103+$ isolate carrying a plasmid that expresses GFP (103S-GFP). Additionally, seven low-passage clinical isolates (1-3 passages) were included. All isolates were routinely cultured from glycerol stocks stored at $-80{ }^{\circ} \mathrm{C}$ onto brain heart infusion (BHI; BD Difco, Sparks, MD) agar plates incubated at $37^{\circ} \mathrm{C}$ for $24-48 \mathrm{~h}$.

All strains were confirmed to be $R$. equi by colony polymerase chain reaction (PCR) with crude genomic DNA isolated using Instagene matrix (Bio-Rad Laboratories Ltd., Hercules, CA), as previously described [18]. Primers targeting the $c h o E$ gene were used to confirm the species (F: 5'-GCTCGCTTCCAGTTCAATTC-3'; R: 5'-AGC GGGTGGTATGTGAAGTC-3'; 188 bp amplicon), vapA primers confirmed the presence of the virulence-associated gene vapA (F:5'-GACTCTTCACAAGACGGT $-3^{\prime}$ [19]; R: 5'-CGAAGTCGTCGAGCTGTCATAG-3' [20]; 189 bp amplicon) on the virulence-associated plasmid VAP, and primers for the $16 \mathrm{~S}$ ribosomal RNA gene were used as a global positive control (F: 5'-AGAGTT TGATCMTGGCTCAG-3' [19]; 5'-GCTGCCTCCCGT AGGAGT-3'; 311 bp amplicon). A PCR program was run with $3 \mathrm{~min}$ initial denaturation at $95{ }^{\circ} \mathrm{C}$, then 35 cycles of $30 \mathrm{~s}$ denaturation at $95{ }^{\circ} \mathrm{C}, 30 \mathrm{~s}$ annealing at $57{ }^{\circ} \mathrm{C}$, and $15 \mathrm{~s}$ extension at $68{ }^{\circ} \mathrm{C}$, followed by a final elongation for $6 \mathrm{~min}$ at $68{ }^{\circ} \mathrm{C}$. PCR products were visualized under UV light following gel electrophoresis in a $1 \%$ agarose gel containing $1 \times$ GelRed nucleic acid stain (Phenix Research Products, Candler, NC).

\section{Growth}

All isolates were grown three ways: in liquid media with shaking to measure the rate of planktonic growth; on solid media to measure colony appearance and size over time; and in static culture in 96-well microtiter plates incubated for up to $72 \mathrm{~h}$, to evaluate biofilm formation.

Growth in liquid media For each strain, a single colony isolate from a BHI agar plate (cultured as described above) was standardized and inoculated to $\sim 10^{5}$ colony forming units (CFU) per $\mathrm{mL}$ in $5 \mathrm{~mL}$ of pre-warmed $\mathrm{BHI}$ broth in a $17 \times 100 \mathrm{~mm}$ plastic culture tube (Falcon, Corning, NY). Cultures were incubated at $37{ }^{\circ} \mathrm{C}$ with $100 \mathrm{rpm}$ shaking for $40 \mathrm{~h}$ (until growth plateaued), $\mathrm{OD}_{600 \mathrm{~nm}}$ was measured, and cells were enumerated by serial dilution and plate counts to determine CFU/mL immediately after inoculation ( $0 \mathrm{~h}$ post-inoculation; hpi), at $4 \mathrm{~h}$ intervals from 0 to $24 \mathrm{hpi}$, and again at $40 \mathrm{hpi}$. All growth curves were repeated three times for strains that grew consistently and up to six times for strains that exhibited some variation in their growth curves.

Growth on solid media To measure colony size development over time on solid media, BHI broth cultures for each strain were serially diluted in PBS, $100 \mu \mathrm{L}$ was spread onto BHI agar plates and incubated at $37{ }^{\circ} \mathrm{C}$ for $48 \mathrm{~h}$. Colony diameters were measured every $4 \mathrm{~h}$ from 24 to $48 \mathrm{hpi}$ using a ruler and calipers, as previously described [21]. Experiments were repeated on three separate occasions, and each colony was treated as a biological replicate.

\section{Biofilm assay}

A biofilm formation assay was conducted as previously described [22], with some modifications. Briefly, cultures were inoculated as described for liquid growth curves to standardize the inoculum to an input CFU of $\sim 10^{5}$ $\mathrm{CFU} / \mathrm{mL}$, which was confirmed by serial dilution and plate counts. For each strain, $100 \mu \mathrm{L}$ of bacterial culture at $0 \mathrm{hpi}$ were added to four replicate wells of a 96-well plate (CoStar, tissue culture-treated, Corning, NY). Two 
positive control strains known to form biofilms, Staphylococcus aureus ATCC 29213 and Pseudomonas aeruginosa ATCC 27853, were also added to each plate for visual comparison of biofilm formation. Four uninoculated BHI broth wells were included per plate to get a blank for calculations. For each experimental day, three identical 96-well plates were incubated at $37{ }^{\circ} \mathrm{C}$ for 24 , 48 , or $72 \mathrm{~h}$, respectively, at which point the broth was removed by gentle suction and inversion onto paper towel. Wells were heat fixed at $56{ }^{\circ} \mathrm{C}$ for $20 \mathrm{~min}$, stained with crystal violet $(0.1 \%)$, washed $3-5$ times with distilled water (until the water ran clear), air dried, and de-stained with $70 \%$ ethanol. Absorbance was measured at $595 \mathrm{~nm}$ using an Epoch plate reader (BioTek Instruments Inc., Winooski, VT), BHI wells were used to blank experimental wells and absorbance results were standardized to input CFU for each strain as previously described [22]. The assay was repeated four separate times per strain. Four empty wells per plate were also stained with crystal violet alongside experimental wells in order to confirm that the plasticware did not retain any stain.

\section{Statistics}

Data were analyzed using a commercial software (SigmaPlot, SPSS, Chicago, Illinois, USA). The Shapiro-Wilk test was used to test for normality. CFU/mL, colony size, and absorbance were compared using one-way analysis of variance (ANOVA) or Kruskal-Wallis one-way ANOVA on ranks. Multiple comparisons were performed using Fisher LSD or Dunn's methods, respectively. Significance was set at $\mathrm{p}<0.05$.

All raw data collected and used for statistical analyses can be accessed in Additional file 1.

\section{Results and discussion}

The purpose of this study was to determine whether low-passage-rate $R$. equi clinical isolates were phenotypically different than the higher-passage-rate isolates. $R$. equi is a prevalent opportunistic pathogen that causes a high financial burden on the horse industry worldwide, but there is limited information on potential differences between $R$. equi strains and the implications this may have on disease development in foals. Most studies to date have been performed using a few strains of $R$. equi (namely 103+, 33701, or UKVDL206), but here we demonstrate that there are differences between strains in the three phenotypic characteristics we evaluated. The implications these differences may have in in vitro studies remain undefined.

The low-passage-rate strains (WSU001-007) were isolated from foals except for WSU001, which was isolated from a human. All isolates were confirmed to be $R$. equi as they tested positive for $c h o E$ by PCR. All isolates except for ATCC 33701 pc also tested positive for the vapA virulence-associated gene (data not shown) and are therefore considered pathogenic to horses.

To determine whether measurable differences among strains existed, isolates were grown in liquid and on solid media, and their ability to form biofilms in vitro was measured (summarized in Table 2 and Additional file 2: Table S1). A study of Pseudomonas aeruginosa using the same three growth methods employed here found that biofilms more closely resemble exponentially growing planktonic cells and that solid and liquid media growth yield similar protein expression profiles [23], suggesting that these three modes of growth may provide a better in vitro model of bacterial growth than employing one method alone. Using data from liquid growth curves (Additional file 2: Fig. S1; Additional file 2: Table S2), generation times were calculated and sorted from fastest- to slowest-growing isolates (Fig. 1). Natural breakpoints in generation times divided isolates into four groups: fast (0.9-0.93 h generation times), moderatefast (1.01-1.05 h), moderate-slow (1.12-1.16 h), or slow $(1.22-1.31 \mathrm{~h})$ growers. The fast and moderate-fast groups were comprised entirely of low-passage-rate isolates. The moderate-slow group contained the higher-passagerate isolates 103+, UKVDL206, ATCC 33701, and 33701 pc. The slow group had one low-passage isolate and the sub-cultured 103S-GFP laboratory strain. The three fast strains grew significantly $(\mathrm{p}<0.001)$ faster than the moderate-slow strains. The fast and moderate-fast isolates all grew significantly $(\mathrm{p}<0.001)$ faster than slow isolates.

Differences were observed in the rate of colony appearance on solid media for the isolates studied; therefore, colony sizes were measured from 20 to $48 \mathrm{~h}$ to see whether this corresponded with liquid culture generation times (Table 2; Additional file 2: Fig. S2). The slow-grower 103S-GFP had the smallest colonies on solid media, but no other obvious commonalities were observed between solid and liquid growth. There have been no reports in the literature on the different rates of growth of $R$. equi strains on solid media, but colony size can be affected by the amount of capsule or extracellular polymeric substance (EPS) produced by a given strain [24]. Further examination of capsule expression would be required to validate this hypothesis.

The ability of $R$. equi to form biofilms has been previously reported $[25,26]$, therefore biofilm formation was examined here. Biofilm production varied greatly between strains (Fig. 1). UKVDL206 formed the most biofilm, while slow-grower WSU006 formed the least. Biofilm formation at 24 and $48 \mathrm{~h}$ showed no significant differences among isolates (data not shown). Using the cut-off imposed by Gressler et al. [25], whereby $R$. equi strains were deemed to be biofilm-producers if 
Table 2 Summary of results for liquid growth (generation time), solid growth (final colony diameter), and biofilm formation

\begin{tabular}{|c|c|c|c|c|}
\hline \multirow{3}{*}{$\begin{array}{l}\text { Isolate } \\
\text { WSU002 }\end{array}$} & \multirow{2}{*}{\multicolumn{2}{|c|}{$\frac{\text { Liquid culture }}{\text { Generation time (h) (fastest to slowest) }}$}} & \multirow{3}{*}{$\begin{array}{l}\text { Solid culture } \\
\text { Colony diameter at } \mathbf{4 8} \mathbf{~ h p i ~ ( m m ) ~} \\
4.56 \pm 0.17\end{array}$} & \multirow{3}{*}{$\begin{array}{l}\text { Biofilm }\left(A_{595} / \log _{10} C F U\right) \\
0.108 \pm 0.013\end{array}$} \\
\hline & & & & \\
\hline & $\mathrm{F}$ & $0.90 \pm 0.02$ & & \\
\hline WSU003 & $\mathrm{F}$ & $0.91 \pm 0.02$ & $3.50 \pm 0.27$ & $0.088 \pm 0.016$ \\
\hline WSU005 & $\mathrm{F}$ & $0.93 \pm 0.05$ & $3.95 \pm 0.18$ & $0.051 \pm 0.006$ \\
\hline WSU001 & MF & $1.01 \pm 0.05$ & $3.75 \pm 0.15$ & $0.091 \pm 0.013$ \\
\hline WSU004 & MF & $1.04 \pm 0.03$ & $5.17 \pm 0.10$ & $0.096 \pm 0.011$ \\
\hline WSU007 & MF & $1.05 \pm 0.03$ & $3.86 \pm 0.19$ & $0.084 \pm 0.012$ \\
\hline $103+$ & MS & $1.12 \pm 0.08$ & $3.06 \pm 0.30$ & $0.118 \pm 0.024$ \\
\hline UKVDL206 & MS & $1.13 \pm 0.06$ & $3.19 \pm 0.23$ & $0.143 \pm 0.023$ \\
\hline ATCC 33701 & MS & $1.16 \pm 0.02$ & $5.38 \pm 0.42$ & $0.091 \pm 0.012$ \\
\hline ATCC 33701 pc & MS & $1.16 \pm 0.04$ & $5.08 \pm 0.27$ & $0.080 \pm 0.010$ \\
\hline WSU006 & S & $1.22 \pm 0.04$ & $3.30 \pm 0.33$ & $\underline{0.045 \pm 0.006}$ \\
\hline 103S-GFP & S & $1.31 \pm 0.04$ & $\underline{1.94 \pm 0.21}$ & $0.122 \pm 0.024$ \\
\hline
\end{tabular}

Generation time results are shown from fastest to slowest growing strain

Italics numbers indicate the largest value among the strains

Underline indicate the smallest value among the strains

F fast-growing, MF moderate-fast-growing, MS moderate-slow-growing, $S$ slow-growing

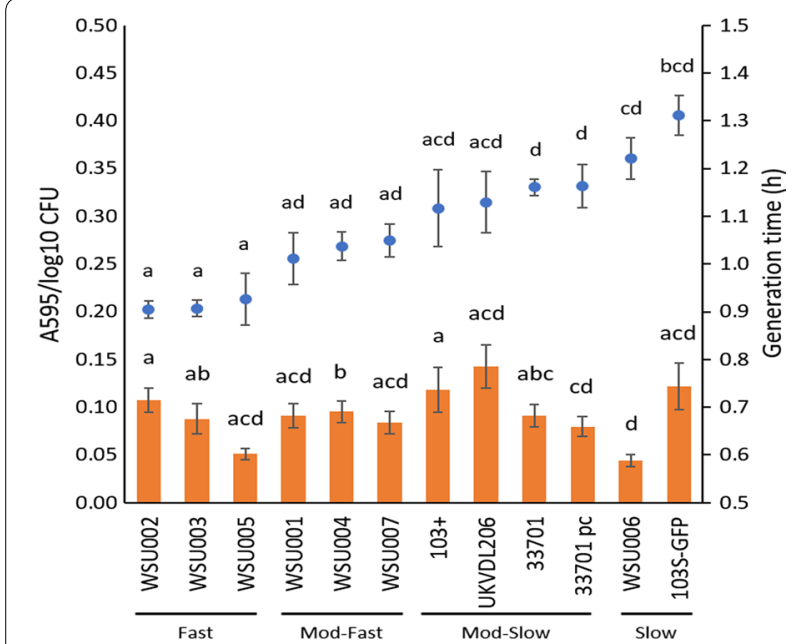

Fig. 1 Biofilm formation of $R$. equi strains after $72 \mathrm{~h}$ of growth in a 96 -well microtiter plate incubated at $37^{\circ} \mathrm{C}$ (left axis, bars) and generation time (right axis, scatter plot). Biofilm results are normalized to $\log _{10}$ input CFU of the initial inoculum. (Error bars represent SEM.

Strains with differing superscript letters are significantly different from one another, $p<0.05$ )

the crystal violet staining exceeded the negative control, all 12 isolates in our study were considered biofilm-producers. While this is consistent with results reported by others [27], some have reported $R$. equi strains that lack the ability to form biofilms in vitro [26]. In the present study, 103+ and 103S-GFP were relatively high biofilm formers, suggesting that the presence of the GFP plasmid did not affect this phenotype. The loss of the VAP did not affect the rate of biofilm formation of 33701, suggesting that most biofilm-associated genes are chromosomally encoded rather than plasmid-encoded. The lack of difference in growth rates between the plasmid-cured and VAP-carrying 33701 strains may be due to the fact that isolates were only grown at one temperature $\left(37{ }^{\circ} \mathrm{C}\right)$. While plasmid-bearing cells have been shown to replicate slower than plasmid-cured derivatives, such differences were dependant on incubation temperature [28]. Overall, there were no obvious shared trends between growth and biofilm experiments under the conditions examined.

In summary, the 103 isolates grew more slowly in liquid, formed smaller colonies on solid media, but formed more biofilm than most strains tested. UKVDL206 grew more slowly in liquid, formed smaller-than-average colonies on solid media, but produced the most biofilm. WSU006 grew slowly and plateaued earlier than most isolates in liquid culture, produced the least biofilm, but formed slightly largerthan-average colonies on solid media. Strains 33701 and 33701 pc grew moderately-slowly but had larger colonies on solid media; however, both were only average biofilm formers. Finally, WSU007 was among the moderately-fast-growing strains but plateaued and declined early in liquid culture, had only moderatelylarge colonies on solid media, and was a moderate biofilm former. 


\section{Conclusions}

The results of this study demonstrate substantial strainto-strain variation in growth rates and biofilm formation of 12 R. equi clinical isolates in vitro. The biological significance of our findings remains unknown; however, our study provides the fundamental basis for further research in this area. Future studies are fundamental to examining whether differences between isolates contribute to the variable outcomes of rhodococcal pneumonia and the foal's ability to clear the infection with or without intervention.

\section{Limitations}

- Low number of strains studied.

- Few avirulent isolates included.

- Growth in rich rather than minimal media.

\section{Additional files}

Additional file 1. Raw data and calculations for the growth parameters of twelve R. equi isolates. Raw data collected to measure liquid and solid media growth and biofilm formation, as well as calculations done to determine the generation times in liquid media for each isolate.

Additional file 2: Table S1. Summary of results for liquid growth (generation time), solid growth (final colony diameter), and biofilm formation. Generation time results are shown from fastest to slowest growing strain. All other results are shown from highest to lowest value. Table S2. Significant differences observed between strains in liquid growth over time. Figure S1. Growth profiles of R. equi strains over time grown in $\mathrm{BHI}$ broth at $37^{\circ} \mathrm{C}$ with $100 \mathrm{rpm}$ shaking. (F: Fast-growing; MF: Moderate-fast; MS: Moderate-slow; S: Slow. Error bars represent SEM). Figure S2. Discrete R. equi colony sizes $(\mathrm{mm})$ for 12 strains over time grown on $\mathrm{BH}$ agar plates incubated $37^{\circ} \mathrm{C}$ for $48 \mathrm{~h}$. (Error bars represent SEM).

\section{Acknowledgements}

The authors wish to thank Dr. Hines and Debby Alperin for generously donating strains WSU001-005, WADDL for providing WSU006 and WSU007, and Drs. Giguère and Hondalus for providing 103S-GFP.

\section{Authors' contributions}

Study was designed by ARB, MS, and NRL. Data collection was conducted by NRL and ARB. Data analysis and statistics were done by ARB and MS. Manuscript preparation was done by ARB, MS, and NRL. All authors read and approved the final manuscript.

\section{Funding}

Funding for this study was provided by intramural grant from internal WSU resources. Beyond provision of funding, the funder was not involved in the design, data collection, analysis, interpretation of the data, or in the writing of the manuscript.

\section{Availability of data and materials}

All data generated or analysed during this study are included in this published article and in Additional file 1.

\section{Ethics approval and consent to participate}

Not applicable.

\section{Consent for publication}

Not applicable.

\section{Competing interests}

The authors declare that they have no competing interests.

Received: 19 June 2019 Accepted: 10 August 2019

Published online: 19 August 2019

\section{References}

1. Vazquez-Boland JA, Giguere S, Hapeshi A, MacArthur I, Anastasi E, ValeroRello A. Rhodococcus equi: the many facets of a pathogenic actinomycete. Vet Microbiol. 2013;167(1-2):9-33.

2. Giguere S, Prescott JF. Clinical manifestations, diagnosis, treatment, and prevention of Rhodococcus equi infections in foals. Vet Microbiol. 1997:56(3-4):313-34

3. Takai S, Ohbushi S, Koike K, Tsubaki S, Oishi H, Kamada M. Prevalence of virulent Rhodococcus equi in isolates from soil and feces of horses from horse-breeding farms with and without endemic infections. J Clin Microbiol. 1991;29(12):2887-9.

4. Prescott JF. Rhodococcus equi: an animal and human pathogen. Clin Microbiol Rev. 1991:4(1):20-34.

5. Toyooka K, Takai S, Kirikae T. Rhodococcus equi can survive a phagolysosomal environment in macrophages by suppressing acidification of the phagolysosome. J Med Microbiol. 2005;54(Pt 11):1007-15.

6. Fernandez-Mora E, Polidori M, Luhrmann A, Schaible UE, Haas A. Maturation of Rhodococcus equi-containing vacuoles is arrested after completion of the early endosome stage. Traffic. 2005;6(8):635-53.

7. Hines M. Rhodococcus equi. In: Sellon DC, Long MT, editors. Equine infectious diseases. 2nd ed. St. Louis: Saunders/Elsevier; 2014. p. 287-302.

8. Takai S, Koike K, Ohbushi S, Izumi C, Tsubaki S. Identification of 15- to 17-kilodalton antigens associated with virulent Rhodococcus equi. J Clin Microbiol. 1991:29(3):439-43.

9. Takai S, Sekizaki T, Ozawa T, Sugawara T, Watanabe Y, Tsubaki S. Association between a large plasmid and 15- to 17-kilodalton antigens in virulent Rhodococcus equi. Infect Immun. 1991;59(11):4056-60.

10. Anastasi E, MacArthur I, Scortti M, Alvarez S, Giguere S, Vazquez-Boland JA. Pangenome and phylogenomic analysis of the pathogenic actinobacterium Rhodococcus equi. Genome Biol Evol. 2016;8(10):3140-8.

11. Letek M, Gonzalez P, Macarthur I, Rodriguez H, Freeman TC, Valero-Rello A, Blanco M, Buckley T, Cherevach I, Fahey R, et al. The genome of a pathogenic rhodococcus: cooptive virulence underpinned by key gene acquisitions. PLoS Genet. 2010;6(9):e1001145.

12. Morton AC, Baseggio N, Peters MA, Browning GF. Diversity of isolates of Rhodococcus equi from Australian thoroughbred horse farms. Antonie Van Leeuwenhoek. 1998;74(1-3):21-5.

13. Cohen ND, Smith KE, Ficht TA, Takai S, Libal MC, West BR, DelRosario LS, Becu T, Leadon DP, Buckley T, et al. Epidemiologic study of results of pulsed-field gel electrophoresis of isolates of Rhodococcus equi obtained from horses and horse farms. Am J Vet Res. 2003;64(2):153-61.

14. Berghaus $\sqcup$, Giguere $S$, Sturgill TL. Effects of age and macrophage lineage on intracellular survival and cytokine induction after infection with Rhodococcus equi. Vet Immunol Immunopathol. 2014;160(1-2):41-50.

15. Sanz MG, Oliveira AF, Page A, Horohov DW. Administration of commercial Rhodococcus equi specific hyperimmune plasma results in variable amounts of IgG against pathogenic bacteria in foals. Vet Rec. 2014;175(19):485.

16. Sanz M, Loynachan A, Sun L, Oliveira A, Breheny P, Horohov DW. The effect of bacterial dose and foal age at challenge on Rhodococcus equi infection. Vet Microbiol. 2013;167(3-4):623-31.

17. Sanz MG, Loynachan A, Horohov DW. Rhodococcus equi hyperimmune plasma decreases pneumonia severity after a randomised experimental challenge of neonatal foals. Vet Rec. 2016;178(11):261.

18. Bujold AR, Maclnnes JI. Identification of putative adhesins of Actinobacillus suis and their homologues in other members of the family Pasteurellaceae. BMC Res Notes. 2015:8:675. 
19. Halbert ND, Reitzel RA, Martens RJ, Cohen ND. Evaluation of a multiplex polymerase chain reaction assay for simultaneous detection of Rhodococcus equi and the vapA gene. Am J Vet Res. 2005;66(8):1380-5.

20. Pusterla N, Wilson WD, Mapes S, Leutenegger CM. Diagnostic evaluation of real-time PCR in the detection of Rhodococcus equi in faeces and nasopharyngeal swabs from foals with pneumonia. Vet Rec. 2007;161(8):272-5.

21. Pirt SJ. A kinetic study of the mode of growth of surface colonies of bacteria and fungi. J Gen Microbiol. 1967;47(2):181-97.

22. Bujold AR, Labrie J, Jacques M, Maclnnes Jl. Differential expression of putative adhesin genes of Actinobacillus suis grown in in vivo-like conditions. Vet Microbiol. 2016;195:60-9.

23. Mikkelsen H, Duck Z, Lilley KS, Welch M. Interrelationships between colonies, biofilms, and planktonic cells of Pseudomonas aeruginosa.J Bacteriol. 2007;189(6):2411-6.

24. Sydor T, von Bargen K, Becken U, Spuerck S, Nicholson VM, Prescott JF, Haas A. A mycolyl transferase mutant of Rhodococcus equi lacking capsule integrity is fully virulent. Vet Microbiol. 2008;128(3-4):327-41.

25. Gressler LT, de Vargas AC, da Costa MM, Sutili FJ, Schwab M, Pereira DIB, Sangioni LA, Botton SD. Biofilm formation by Rhodococcus equi and putative association with macrolide resistance. Pesqui Vet Brasil. 2015;35(10):835-41.

26. Remuzgo-Martinez S, Pilares-Ortega L, Alvarez-Rodriguez L, Aranzamendi-Zaldunbide M, Padilla D, Icardo JM, Ramos-Vivas J. Induction of proinflammatory cytokines in human lung epithelial cells during Rhodococcus equi infection. J Med Microbiol. 2013;62(Pt 8):1144-52.
27. Al Akhrass F, Al Wohoush I, Chaftari AM, Reitzel R, Jiang Y, Ghannoum M, Tarrand J, Hachem R, Raad I. Rhodococcus bacteremia in cancer patients is mostly catheter related and associated with biofilm formation. PLOS ONE. 2012;7(3):e32945.

28. Takai S, Sugawara T, Watanabe Y, Sasaki Y, Tsubaki S, Sekizaki T. Effect of growth temperature on maintenance of virulent Rhodococcus equi. Vet Microbiol. 1994;39(1-2):187-92.

29. Takai S, Hines SA, Sekizaki T, Nicholson VM, Alperin DA, Osaki M, Takamatsu D, Nakamura M, Suzuki K, Ogino N, et al. DNA sequence and comparison of virulence plasmids from Rhodococcus equi ATCC 33701 and 103. Infect Immun. 2000;68(12):6840-7.

30. Burton AJ, Giguere S, Berghaus LJ, Hondalus MK, Arnold RD. Efficacy of liposomal gentamicin against Rhodococcus equi in a mouse infection model and colocalization with $R$. equi in equine alveolar macrophages. Vet Microbiol. 2015;176(3-4):292-300.

31. Prescott JF. Capsular serotypes of Corynebacterium equi. Can J Comp Med. 1981;45(2):130-4.

\section{Publisher's Note}

Springer Nature remains neutral with regard to jurisdictional claims in published maps and institutional affiliations.
Ready to submit your research? Choose BMC and benefit from:

- fast, convenient online submission

- thorough peer review by experienced researchers in your field

- rapid publication on acceptance

- support for research data, including large and complex data types

- gold Open Access which fosters wider collaboration and increased citations

- maximum visibility for your research: over $100 \mathrm{M}$ website views per year

At BMC, research is always in progress.

Learn more biomedcentral.com/submissions 